\title{
Realisasi Literasi Lingkungan Melalui Workshop Mikro Organisme Lokal (MOL)
}

\author{
Hari Kusmanto $^{1}$, Rohmad Darmawan ${ }^{2}$, Bella Kisnaria ${ }^{3}$, Yulianto Bambang Setiyadi ${ }^{4}$ \\ ${ }^{1,2,3,4}$ Fakultas Keguruan dan Ilmu Pendidikan, Universitas Muhamamdiyah Surakarta, Indonesia
}

\section{INFORMASI ARTIKEL}

\section{Histori Artikel:}

Submit : 5 Juni 2019

Direvisi : 18 Juni 2019

Diterima : 26 Juni 2019

Publikasi : 1 Juli 2019

\section{Kata Kunci:}

mol

literasi lingkungan

revitalisasi struktur tanah

\section{Correspondent Author:}

Hari Kusmanto

Fakultas Keguruan dan Ilmu Pendidikan

Universitas Muhammadiyah Surakarta,

Indonesia

Email:

a310150036@student.ums.ac.id

\begin{abstract}
ABSTRAK
Studi ini bertujuan untuk mendekripsikan strategi, pengaruh, dan kelebihan serta kekurang MOL sebagai pupuk cair. Langkah-langkah yang dilakukan meliputi: (1) persiapan meliputi (a) Persiapan Media; (b) Persiapan Tanaman. (2) Penanaman; (3) Pemberian MOL Bonggol Pisang Dan Buah; (4) Pemeliharaan; dan (5) Pemanenan. Hasil studi menunjukkkan (1) strategi yang dapat dilakukan untuk menekan biaya produksi pertanian dengan cara pemanfaatan MOL sebagai penguat pupu kimia; (2) meningkatkan kualitas tanaman Tanaman menjadi lebih kuat, sehat, daun tanaman menjadi lebih hijau sehingga tidak memerlukan pupuk daun; akar menjadi lebih kuat; memperbanyak jumlah bulir padi sehingga hasil panen lebih banyak; menyiapkan tanaman berbungan dan berbuah agar buah bagus (3) kelebihan MOL diantaranya (a) Meningkatkan kesuburan tanah dan memperbaiki kondisi biologi, fisika dan kimia tanah sehingga unsur-unsur hara dalam tanah bisa dimanfaatkan tanaman secara maksimal; (b) Membantu peningkatan hasil panen 20-30\% gabah kering per 100 bata; (c) Dapat menghemat penggunaan pupuk kima 25-50\%; (d) Membantu penguraian racun dalam tanah; dan (e) Membantu meningkatkan kesuburan tanah. (4) Kekurangan mol diantaranya sebagai berikut (a) belum adanya penjual yang menjual MOL sehingga petani harus membuat sendiri; (b) Manfaat MOL dapat di peroleh setelah penggunaan mol secara bertahap artinya dalam satu kali penggunaan mol kemungkinan besar dampaknya atau pengaruhnya belum terlihat atau belum dapat dirasakan.
\end{abstract}

\section{Pendahuluan}

Kelangkaan pupuk kimia yang terjadi pada akhir tahun 2018, khususnya di Desa Kalikebo, Kecamatan Trucuk dan kecamatan sekitarnya Kabupatem Klaten. Kenailkan yang tinggi hingga dua kali lipat. Namun petani tetap membeli pupuk demi menjaga produksi tanamannya meskipun biaya operasional pertanian akan bertambah. Hal tersebut menunjukkan petani betapa tergantungnya pada pupuk kimia.
Petani lebih memperhatikan kepentingan sesaat dari pada kepentingan jangka panjang. Pemakain pupuk kimia terutama dalam jumlah berlebihan di atas takaran rekomendasi selama ini sudah mulai memberikan dampak lingkungan yang negatif seperti kualitas lahan sawah menurun, cepat mengeras, daya serap air dan keberadaan hara kurang, menurunnya mikroba tanah dan lain-lain.

Dampak pemakaian pupuk kimia mempunyai efek yang cepat dalam 
meningkatkan produksi tetapi dengan kadar yang tidak seimbang. Hal tersebut kemampuan lahan over dosis dan rusak. Menurut kartiadi (dalam syaifuddin, ) menegaskan bahwa seberapa tinggi lahan pertanian sakit karena pemakaian pupuk kimia adalah melalui indikator kesuburan tanah yaitu kandungan COrganik. Komponen C-Organik dari $65 \%$ tanah persawahan di indonesia di bawah $1 \%$ yang harusnya di atas 2\%. Artinya tanah itu sudah mulai rusak.

Dari berbagai akibat penggunaan pupuk kimia tersebut masalah yang timbul antara lain: 1) tanaman menjadi sangat rawan terhadap hama, meskipun produksi tanaman tingi tetapi tiak memiliki ketahanan terhadap hama. 2) pembodohan terhadap petani karena hilangnya pengetahuan lokal dalam mengelola lahan pertanian, petani bergantung pada teknologi pertanian.

Salah satu solusi yang dapat di laukukan dari kenyataan di atas ialah dengan menggunakan MOL (Mikro Organisme Lokal) sebagai penunjang pupuk kimia. Larutan MOL adalah larutan hasil fermentasi yang berbahan dasar berbagai sumber daya yang berada di lingkungan sekitar. Larutan MOL mengandung unsur hara mikro dan makro dan juga mengandung bakteri yang berpotensi sebagai perombak bahan organik, perangsang pertumbuhan, dan sebagai agen pengendali hama dan penyakit tanaman, sehingga MOL dapat digunakan baik sebagai pendekomposer, pupuk hayati, dan sebagai pestisida khususnya untuk fungisida. (purwasasmita, 2009)

Keunggulan MOL yang paling utama ialah murah, karena bahan yang mudah di dapat. Denga memanfaatkan bahan-bahan yang ada disekitar, petani dapat membuat MOL dari bahan-bahan seperti, buah-buahan busuk, rebung, dedaunan, urine hewan, dan sebagainya.

Surjano (dalam Firdaus, 2011:6) Pisang mempunyai kandungan gizi yang sangat baik antara lain menyediakan energi cukup tinggi dibandingkan dengan buah-buahan lain. Pisang kaya kandungan mineral seperti kalium, fosfor, besi, dan kalsium. Pisang juga mengandung vitamin yaitu C, B kompleks, B6 dan serotonin yang aktif sebagai neurotransmitter dalam kelancaran fungsi otak.

Small (dalam Firdaus, 2011:6) Batang pisang sebagian berisi air dan serat (selulosa), disamping mineral, kalium dan fosfor. Komposisi kimia batang pisang dipengaruhi oleh berbagai faktor yaitu komposisi tanah, frekuensi pemotongan, fase pertumbuhan, pemupukan, iklim setempat dan ketersediaan air. Serat batang pisang mengandung 63\% selulosa, 20\% hemiselulosa dan 5\% lignin.

Nisa et.al (2016) Mengemukakan Buahbuahan busuk yang tidak bisa dimakan lagi bisa dimanfaatkan sebagai MOL. MOL yang dibuat dari buah busuk dapat digunakan untuk untuk pengomposan maupun untuk disemprotkan pada tanaman. Buah busuk yang dapat digunakan adlah buah apa saja seperti: pepaya, mangga, apel, salak, dll.

Seni et.al.(2013) meneliti tentang "Analisis Kualitas Larutan MOL (Mikro Organisme Lokal) Berbasis Daun Gamal (Glircilia sepium)." Simpulan atau temuan dari mereka ialah a) konsentrasi daun gamal dan lama fermentasi berpengaruh sangan nyata terhadap kualitas larutan MOL. b) perlakuan konsentrasi daun gamal $600 \mathrm{~g} / \mathrm{L}$ dengan lama tiga minggu memiliki kualitas larutan MOL yang terbaik. 
Julita et.al.(2013) meneliti tentang "Pengaruh Pemberian Mikro Organisme Lokal (MOL) Nasi dan Hormon Tananman Tunggal Terhadap Pertumbuhan Dan

Produksi Tananman Cabai (capsium annum L.)." Simpulan atau temuan dari mereka ialah a) perlakuan MOL nasi dan Hormon tananaman unggul secara interaksi memberikan pengaruh yang nyata terhadap pengamatan umur berbunga dan umur panen pertama dengan perlakuan terbaik M2H2 (MOL nasi 100 cc/L air + Hormon tanaman unggul 2cc/L air). b) perlakuan MOL nasi secara tunggal memberikan pengaruh yang nyata terhadap parameter pengamatan umur berbunga, umur panen pertama, berat buah pertanaman yang ekonomis dan berat buah per plot yang ekonomis dengan perlakuan terbaik M2 (MOL nasi 100cc/L air). c) perlakuan hormon tanaman unggul secara tunggal memberikan pengaruh nyata terhadap pengamatan tinggi tanaman, umur berbunga, umur panen pertama, berat buah pertanaman yang ekonomis, berat buah per plot yang ekonomis dan jumlah buah sisa pertanaman yang tidak ekonomis dengan perlakuan terbaik H2 (hormon tanaman unggul $2 \mathrm{cc} / \mathrm{L}$ air).

Parawansa \& Ramli. (2014) Meneliti tantang "Mikro Organisme Lokal (MOL) Buah Pisang Dan Pepaya Terhadap Pertumbuhan Ubi Jalar (Ipomea Batatas L)." Simpulan atau temuan dari mereka ialah, a) manfaat mikro organisme lokal (MOL) pada tanaman ubi jalar memberikan pengaruh positif pada pertumbuhan panjang batang, jumlah daun dan jumlah tunas. b) dosisi yang terbaik dalam penggunaan MOL terhadap pertumbuhan vegetatif tanaman ubi jalar (ipomea batatas L) yaitu 75 cc L air (M1), memberikan panjang batang $387 \mathrm{~cm}$, jumlah daun 287 helai dan jumlah tunas 87 tanaman ubi jalar.

Riyadi et.al.(2014) Meneliti tentang "Pemanfaatn Limbah Tepung Aren dan Mikro Organisme Lokal Untuk Meningkatkan Hasil Tanaman Cabai Merah Besar." Simpulan atau temuan dari mereka ialah a) limbah aren dapat diolah menjadi pupuk organik untuk budidaya cabai b) perlakuan dengan penambahan nutrisi pengaya pupuk limbah aren dapat meningkatkan tinggi tanaman, berat cabai, panjang cabai, jumlah cabai, berat brangkasan kering. c) pemberian nutrisi pengaya kotoran sapi memberikan rata-rata pertumbuhan tertinggi pada tinggi tanaman sebesar 73,55 cm, berat brangkasan segar 359,44 gram, dan brangkasan kering 76,22 gram. d) pemberian nutrisi pengaya bekatul memberikan rat-rata hasil tertinggi pada berat cabai sebesar 19,66 gram, panjang cabai 10,91 cm, dan jumlah 18,22 buah. Nasution \& syarif (2015) meneliti tentang "pemanfaatan kompos aktif dalam budidaya pepaya organik di desa kasang pudah." Simpuan atau temuan dari mereka iaah a) program pengabdian kepada masyarakat kepada kelompok tani mawar melati dan harapan baru, diterima dengan baik oleh semua anggota kelompok tani partisipasi mitra mencapai $75 \%$ dan meebihi taeget yang direncanakan $50 \%$.

Evita et.al. (2015) meneliti tentang "penggunaan MOL keong murboy sebagai biostarter aktif pada kompos jerami untuk budidaya sayurn organik." Simpulan atau temuan dari mereka ialah a) keompok tani paprika dan kelompok d'terong sudah mampu dan terampi membuat kompos dari jerami padi dengan memakai bistarter MOL keong murbay 
dan akan diperkenakan pada masyarakat sekitarnya.

Fitriana et.al (2015) meneliti tentang "uji efektivitas beberapa mikro organisme lokal terhadap pertumbuhan dan hasil tanaman sawi hijau (brassica juncea L)." Simpulan atau emuan dari meraka ialah a) pemberian beberapa macam MOL pada tanaman sawi tidak berpengaruh nyata terhadap tinggi tanaman, jumlah daun, berat kering tanaman, berat segar tanaman dan hasil.

Kusniadi et.al. (2015) meneliti mengenai "penambahan gedebog pisang pada kompos bulu ayam dengan berbagai jenis aktovator." Simpulan atau temuan dari mereka ialah a) penambhan gedebog pisang berpengaruh terhadap sifat fisik kompos pada pengubah kadar air dan berpengaruh pada sifat kimia kompos dengan peubah $\mathrm{C} / \mathrm{N}$ rasio dan kadar kalium. b) penggunaan mikroorganiseme lokal (MOL) efektif digunakan sebagi aktivator pengomposan limbah bulu ayam dan gedebog pisang. c) terdapat interaksi antara penambahan gedebog pisang dengan aktivator pada sifat kimia kompos dengan perubahan $\mathrm{C} / \mathrm{N}$ rasio yaitu dengan penambahan gedebog pisang, sebanyak $1 \mathrm{~kg}$ menggunakan MOL pepaya sebagi aktivator.

Marsinih et.al. (2015) meneliti mengenai "analisis kualitas MOL (Mikro Organisme Lokal) berbasis ampas tahu." Simpulan tau temuan dari mereka ialah a) interaksi konsentrasi ampas tahu dan lama fermentasi berpengaruh sangat nyata. Terhadap parameter tota populasi bakteri, total populasi jamur, Ntotal, dan Ptersedia larutan MOL, akan tetapi berpengaruh tidak nyata terhadap PH larutan MOL. kualitas larutan MOL terbaik (29,80x10 spk ML MOL), N-total (0,06\%), dan P-tersedia
$(199,38 \mathrm{mg} \mathrm{kg})$ terdapat pada perlakuan konsentrasi $600 \mathrm{~g}$ ampas tahu dengan lama fermentasi lima minggu.

Suryanto et.al. (2015) meneliti mengenai “ efektivitas Trichoderma sp dan mikro organisme lokal (MOL) sebagai dekomposer dalam meningkatkan kualitas pupuk organik alami dari beberap limbah pertanian". Simpulan atau temuan dari mereka ialah a) kandungan hara bahan kompos jerami lebih tinggi dibandingkan bahan sabut kelapa dan tandan kosong kelapa sawit. Selama proses pengomposan bahan kompos yang berasal dari jerami padi lebih cepatmengalami perubahan fisik. Dekomposer campuran Trichoderma sp dan MOL lebih cepat dalam melakuan perubahan sifat fisik bahan kompos. Bahan kompos jerami padi dengan dekomposer Trichoderma sp dan MOL menghasilkan C/N yang lebih rendah dan unsur hara N, P, K, Ca dan $\mathrm{Mg}$ yang lebih tinggi dibandingkan bahan dan dekomposer yang lain.

Nugraha \& Acep (2015) meneliti mengenai "respon tanaman padi (Oryza Sativa L) kuitivar inpari 30 akibat pemberian berbagai dosis pupuk Anorganil dan mikro organisme lokal (MOL)." Simpulan tau temuan dari mereka ialah, a) tidak terjadi interaksi pemberian dosis pupuk anorganik dan macam MOL. efek mandiri dari pemberian dosis pupk anorganik berpengaruh nyata pada bobot ubinan (taraf perlakuan $\mathrm{P} 3=$ dosis $300 \mathrm{~kg}$ urea/hektar + $200 \mathrm{~kg}$ NPK/hektar).

Riduan et.al. (2015) meneliti tentang "aplikasi penggunaan pupuk organik budidaya ubi jalar di desa muaro pijoan kabupaten muaro jambi." Simpulan atau temuan dari mereka ialah, a) bududaya ubi jalar organik dapat meningkatkan hasil ubi jalar dan menekan 
kerusakan hasil ubi jalar akibat serangan penyakit, b) bududaya ubi jalar organik dapat dilakukan denganbiaya yang rendah karena menggunakan pupuk dari bahan yang ada di sekitar kita dan ramah lingkungan, c) program pengabdian ini menghasilkan output: MOL batang pisang, bonggol pisang dan serabut kelapa.

Rahmayani et.al. (2016) meneliti mengenai "pengaruh penggunaan ampas tahu terhadap kadar nitrogen pupuk organik dari endapan limbah cair kelapa sawit menggunakan mikro organisme lokal." Simpulan atau temuan mereka ialah, a) komposit endapan limbah cair pabrik kelapa sawit, MOL dan ampas tahu pada perbandingan 1:1:1 dan difermentasi selama 14 hari menghasilkan pupuk organik terbaik dengan kadar Nitrogen total 2,30\%, b) komposit endapan limbah cair pabrik kelapa sawit dan MOL perbandingan 1:1 dan difermentasi selama 28 hari menghasilkan bahan baku pupuk organik yang paling optimal dengan kadar Nitrogen total 1,6\%, c) komposit endapan limbah cair pabrik kelapa sawit dan MOL yang difermentasi 28 hari menggunakan ampas tahu sebagai filter pada perbandingan 1:1:1,25 mampu menghasilkan pupuk organik terbaik dengan kadar Nitrogen 2,41\%.

Suhastyo et.al. (2016) meneliti mengenai "respon tanaman kedelai terhadap pemberian Mikro Organisme Lokal (MOL) bonggol pisang dan pupuk kandang kotoran sapi." Simpulan atau sapi belum mampu dengan kadar konsentrasi $5 \mathrm{~L}$ ha menunjukkan hasil tertinggi pada bobot kering tanaman, jumlah polong dan jumlah biji per tanaman yang berturt-turut 103,109; 50,00 polong dan 72,67 buah, sedangkan konsentrasi 2,5 L h menunjukkkan hasi tertinggi pada bobot 100 biji yaitu 5,939.
Pemberian pupuk kandangkotoran sapi dosis 10 tan per ha menunjukkan hasil tertinggi pada bobot kering tanaman, jumlah biji dan bobot 100 biji yang berturut-turut 85,799; 61, 89 buah dan 6, 119, sedangkan dasis 5 ton ha menunjukkan hasil tertingipada jumlah polong yaitu 43, 67 polong. Serta tidak ada interaksi antara pemberian MOL bonggol pisang dan pupuk kandang kotoran sapi dengan seluruh parameter pertumbuhan dan hasil kedelai.

\section{Metode Pelaksanaan}

Penelitian ini dilaksanakan pada bulan februari 2019. Penelitian ini dilaksanakan di Desa Kalikebo, Kecamatan Trucuk, Kabupaten Klaten. Alat yang digunakan dalam penelitian ini adalah ember, selang, botol, polybag,cangkul, alat siram, ctok. Bahan yang digunakan dalam penelitian ini adalah benih jagung, air, air bersih, gula merah, dll. a. persiapan

1. Persiapan Media

Persiapan media meliputi pembuatan MOL buah, persiapan media tanah dan inkubasi pupuk kandang. Pembuatan MOL buah dilakukan dengan mencampur buah dengan air beras dan gula merah lalu diinkubasi selama 14 hari. Media tanah dan pupuk kandang diletakkan dalam polybag dan dinkubasi selama 7 hari. Inkubasi bertujuan untuk memaksimalkan mineralisasi pupuk kandang.

2. Persiapan Tanaman

Persiapan tanaman meliputi pemilihan benih jagung. Pemilihan benih jagung yang baik dengan ciri benih utuh, dan tidak memiliki penyakit.

a) Penanaman

Penanaman benih jagung dilakukan dengan cara melubangi tanah kurang lebih 8 
cm, setiap satu lubang diberi satu benih jagung.

Kemudian tutup dengan pupuk kandang.

b) Pemberian MOL Bonggol Pisang Dan Buah

Pemberian MOL pada tanaman jagung dilakukan setelah jagung berumur....

c) Pemeliharaan

Pemeliharaan meliputi pengukuran tanaman setiap satu minggu sekali, penyiraman, penyiangan dan pengendalian hama penyakit yang menyerang tanaman.

d) Pemanenan

Pemanenan dilakukan dengan mengambil buah tanaman jagung saja. Kemudian penimbangan jagung segar dan jagung kering.

Data yang diambil adalah data pengukuran tanaman yang diambil setiap satu minggu sekali dan data hasil tanaman jagung baik dalam kondisi segar maupun kering dan dibandingkan anatara tanaman yang di beri perlakuan MOL dan yang tidak di beri perlakuan MOL.

\section{Hasil Pelaksanaan dan Pembahasan}

Musim kemarau saat ini sangat cocok untuk menanam jagung. Hal ini disebabkan karena tanaman jagung tidak banyak membutuhkan air seperti halnya tanaman padi dan kacang tanah. Selain itu perawatan tanaman jagung lebih mudah sehingga akan lebih menghemat biaya produksi.

Musim yang cocok untuk menanam tanaman jagung ialah musim kemarau karena saat musim kemarau tidak banyak air, tanaman jagung yang terlalu banyak air atau kelebihan air akan menghambat pertumbuhan jagung. Ketika pertama jagung ditanam apabila terlalu banyak air biji jagung yang ditanam kemungkinan tidak akan tumbuh karena biji yang ditanam akan busuk. Selain hal itu tanaman jagung ketika saat berbuah kebanyakan air maka, jagung tidak akan berbuah bahkan mati ketika air banyak menggenangi tanaman jagung.

Biya dikeluarkan untuk menanam jagung diantaranya: bibit jagung 78.000,00 × $4=R p$. $312.000,00$. Pupuk urea 100.000,00 x $2=$ Rp. 200.000,00. Pupuk phonskha $125.000,00 \times 2=$ Rp. 250.000,00. Biya untuk tanam 200.000,00. Pengairan 150.000,00. Biaya tersebut digunakan untuk tanah yang memiliki luas 1500 m2. Jagung dapat dipanen setelah berumur antara 90 - 100 hari setelah tanam.

Kendala yang dihadapi oleh petani dalam menanam jagung diantaranya: bibit yang dibeli mengadung penyakit bule atau bibit setelah ditanama karena dengan kondisi lingkungan tidak cocok sehingga tanaman jagung terkena penyakit bule. Apabila jagung terkena penyakit bule, maka jagung tidak akan berbuah. Penyakit bule dapat menular pada tanaman jagung yang lainnya. Penaggulangan tanaman yang terserang penyakit bule dengan cara mencabut tanaman jagung yang terkena penyakit bule dan membuangnya ataupun dengan cara mengubur tanaman jagung yang terkena bule agar tidak menular pada tanaman yang lain. Selain penyakit bule kendala yang dihadapi ketika pertama menanam jagung ialah tikus. Tikus akan memakan biji jagung yang baru di tanam.

Solusi yang akan penulis ajukan ialah cairan pupuk organik yaitu MOL (Mikro Organisme Lokal) adalah larutan hasil fermentasi yang berbagai bahan dasar dari berbagai sumberdaya yang tersedia di sekitar. Dalam hal ini penulis menggunakan bahan dasar bonggol pisang dan buah-buahan. 
Alasan menggunakan MOL karena bahanbahan pembuatan mol banyak tersedia di lingkungan petani. Proses pembuatan mol yang relatif mudah, petani dapat membuat mol sendiri tanpa harus membeli tentunya dapat mengurangi biaya produksi petani.

Bahan-bahan yang perlu dipersiapakan dalam proses pembuatan mol diantaranya:

1. Karbohidrat: air cucian beras (tajin), nasi basi,singkong dan lain-lain. Tetapi yang paling banyak digunakan adalah air cucian beras (tajin).

2. Glukosa: gula merah yang telah diencerkan dengan air (air gula).

3. Sumber bakteri: bongol pisang, buahbuahan yang sudah tidak layak untuk dikonsumsi, urine binatang dan apapun yang mengandung sumber bakteri.

Mol bonggol pisang merupakan mikroorganisme lokal yang berbahan dasar bonggol pisang. Bonggol pisang bahan yang sangat mudah didapat, di sekitar rumah banyak tersedia tanpa harus membeli. Cara pembuatan MOL bonggol pisang:

Bahan:

1. Bonggol pisang minimal $1 \mathrm{~kg}$

2. Gula merah 2 ons

3. Leri (air cucian beras) 2 liter

Cara membuatnya: pertama, tumbuk bonggol pisang sampai halus agar memudahkan dalam proses fermentasi. Kedua, haluskan gula merah hal ini bertujuan untuk memudahkan proses fernentasi agar proses fermentasi berjalan lancar. Ketiga, masukkan semua bahan yang tersedia mulai dari bonggol pisang yang telah ditumbuk, kemudian masukkan gula merah yang telah di haluskan, selanjutnya masukkan leri (air cucian beras) ke dalam derigen yang telah disiapkan. Kemudian tutup derigen tunggu sampai 7-10 hari tempatkan derigen di tempat yang gelap jangan sampai terpapar sinar matahari langsung.

Mol buah merupakan mikroorganisme lokal yang berbahan dasar buah-buahan yang tidak layak dikonsumsi tetapi bukan buah busuk. Buah yang digunakan dalam membuat mol buah-buahan merupakan buah yang tidak layak makan tetapi bukan buah busuk, misalnya buah yang akan busuk. Mengapa Buah yang tidak layak di konsumsi di gunakan sebagai bahan dasar pembuatan mol. Hal ini disebabkan biaya yang dikelurkan tidak banyak, bahkan gratis karena buah tidak layak konsumsi dapat kita peroleh dengan meminta kepada pedagang buah di pasar. Cara pembuatan Mol buah:

Bahan

1. Buah $1 \mathrm{~kg}$ (minimal) buah yang tidak layak di konsumsi tetapi tidak busuk.

2. 1 liter air kelapa.

3. 1 ons gula merah.

Cara membuatnya: pertama, pisahkan buah tidak layak konsumsi dari bijinya, kerena yang dimanfaatkan sebagai bahan dasar pembuatan Mol adalah dagimh buah setelah di pisahkan haluskan daging buah. Kedua, haluskan gula merah dengan cara ditumbuk. Ketiga, masukkan semua bahan kedalam derigen mulai dari buah daging buah yang telah di haluskan kedalam derigen, selanjutnya masukkan 1 liter air kelapa, kemudian masukkan 1 ons gula merah yang telah di haluskan, tutup derigen tunggu sampai 7-10 hari. Saat proses fermentasi hindarkan derigen kontak langsung dengan sinar matahari, tempatkan derigen di tempat yang gelap. Janga membuka tutup derigen sebelum 7 hari. 


\section{Simpulan}

Berdasarkan hasil dan pembahasan yang telah dilakukan maka dapat disimpulkan (1) strategi yang dapat dilakukan untuk menekan biaya produksi pertanian dengan cara pemanfaatan MOL sebagai penguat pupu kimia; (2) meningkatkan kualitas tanaman Tanaman menjadi lebih kuat, sehat, daun tanaman menjadi lebih hijau sehingga tidak memerlukan pupuk daun; akar menjadi lebih kuat; memperbanyak jumlah bulir padi sehingga hasil panen lebih banyak; menyiapkan tanaman berbungan dan berbuah agar buah bagus (3) kelebihan MOL diantaranya (a) Meningkatkan kesuburan tanah dan memperbaiki kondisi biologi, fisika dan kimia tanah sehingga unsurunsur hara dalam tanah bisa dimanfaatkan tanaman secara maksimal; (b) Membantu peningkatan hasil panen 20-30\% gabah kering per 100 bata; (c) Dapat menghemat penggunaan pupuk kima 25-50\%; (d) Membantu penguraian racun dalam tanah; dan (e) Membantu meningkatkan kesuburan tanah. (4) Kekurangan mol diantaranya sebagai berikut (a) belum adanya penjual yang menjual MOL sehingga petani harus membuat sendiri; (b) Manfaat

MOL dapat di peroleh setelah penggunaan mol secara bertahap artinya dalam satu kali penggunaan mol kemungkinan besar dampaknya atau pengaruhnya belum terlihat atau belum dapat dirasakan.

\section{Daftar Pustaka}

Evita et.al. 2015. Penggunaan MOL Keong Murbay Sebagai Biostarter Aktif Pada Kompos Jerami Untuk Budidaya Sayuran Organik. Jurnal Pengabdian Masyarakat, $30,(2): 1-5$.

Firdaus, Febriwendi. 2011. Kualitas Pupuk Kompos Campuran Kotoran Ayam Dan
Batang Pisang Menggunakan

Bioaktivator MOL Tapai. Skripsi.

Fakultas Peternakan Institut Pertanian Bogor.

Fitriani et.al.2015. Uji Efektifitas Beberapa Mikro Organisme Lokal Terhadap Pertumbuhan Dan Hasil Tanaman Sawi Hijau (Brassica Juncea L). Jurnal Penelitian Universitas Jambi Seri Sains, 17, (2): 68-74.

Julita et.al. 2013. Pengaruh Pemberian Mikro Organisme Lokal (MOL) Nasi Dan Hormon Tanaman Unggul Terhadap Pertumbuhan Dan Produksi Tanaman Cabai (Capsicum Annum L). Jurnal dinamika, 28, (3): 167-174.

Kusnaidi et.al. 2015. Penambahan Gedebog Pisang Pada Kompos Bulu Ayam dengan Berbagai Jenis Aktivator. Eviagro Jurnal Pertanian dan Lingkungan, 8, (1): 19-30.

Marsiningsih et.al. 2015. Analisis Kualitas Larutan MOL (Mikro Organisme

Lokal) Berbasis Ampas Tahu. E-jurnal Agroekoteknologi Tropika, 4, (3): 180-190

Nasutio, margaretta hastiati \& muhamad syarif. 2015. Pemanfaatan Kompos Aktif Dalam Budidaya Pepaya Organik Di Desa Kasang Pudak. Jurnal Pengabdian Masyarakat, 30, (3): 16-22

Nugraha, dadan ramdan \& acep atma jaya. 2015. Respon Tanaman Padi (Oryzae Sativa L) Kuitivar Inpari 30 Akibat Pemberian Berbagai Dosis Pupuk Anorganik Dan Macam Mikro Organisme Lokal (MOL). Jurnal Ilmu Pertanian Dan Peternakan, 3,(1): 62-67.

Parawansa, Ismaya NR \& Ramli.2014. Mikro Organisme Lokal (MOL) Buah Pisang Dan Pepaya Terhadap Pertumbuhan Tanaman Ubi Jalar (Ipomea batatas L). Jurnal Agisistem. 10.(1): 10-15.

Rahmayani et.al.2016. Pengaruh Penggunaan Ampas Tahu Terhadap Kadar Nitrogen Pupuk Organik Dari Endapan Limbah Cair Kelapa Sawit Menggunakan Mikro 
Organisme Lokal. Journal of Chemical Process Engginering, 01, (02): 1-6

Riduan et.al. 2015. Aplikasi Penggunaan Pupuk Organik Budidaya Ubi Jalar Di Desa Muaro Pijoan Kabupaten Muaro Pijoan Jambi. Jurnal Pengabdian Masyarakat, $30,(2): 58-65$

Riyadi et.al. 2014. Pemanfaatan Limbah Tepung Aren Dan Mikro Organisme Lokal Untuk Meningkatkan Hasil Tanaman
Cabai Merah Besar (capsium annum L). El-Vivo, 2, (2): 34-4l.

Seni et.al. 2013. Analisis Kualitas Larutan MOL (Mikro Organisme Lokal) Berbasis Daun Gamal (Glaciricida Sepium). E-jurnal Agroekoteknologi Tropika, 2,(2): 135-144. 